\title{
KARAKTERISTIK ANTIBIOGRAM ISOLAT Escherichia coli DAN \\ Klebsiella pneumoniae DARI RUANG INTENSIVE CARE UNIT \\ DAN NON-INTENSIVE CARE UNIT DI RSUP SANGLAH \\ SELAMA TAHUN 2018-2020
}

\section{Ni Luh Ranthi Kurniawathi*, Indramawan Setyojatmiko*, Ni Nyoman Sri \\ Budayanti** $^{* *}$}

*Program Pendidikan Dokter Spesialis Mikrobiologi Klinik, Fakultas Kedokteran Universitas Udayana, Bali, Indonesia

**KSM/ Departemen Mikrobiologi Klinik Fakultas Kedokteran Universitas Udayana/ Rumah Sakit Umum Pusat Sanglah, Bali, Indonesia

Penulis Korespondensi: Ni Nyoman Sri Budayanti, KSM/ Departemen Mikrobiologi Klinik Fakultas Kedokteran Universitas Udayana/ Rumah Sakit Umum Pusat Sanglah,

Bali, Indonesia

Email: nyomansribudayanti@gmail.com

\begin{tabular}{|c|c|c|}
\hline Tanggal Submisi & Tanggal Penerimaan & Tanggal Publish \\
05 September 2021 & 25 November 2021 & 25 Desember 2021 \\
\hline
\end{tabular}

\begin{abstract}
ABSTRAK
Resistesi antibiotik meningkat secara global dalam beberapa tahun ini, terutama kejadian Escherichia coli (E.coli) dan Klebsiella pneumoniae (K.pneumoniae) penghasil Extended Spektrum Beta Lactamases (ESBL). Tujuan dari penelitian ini adalah untuk memberikan gambaran prevalensi keberadaan dan antibiogram isolat E.coli dan $K$. pneumoniae penghasil $E S B L$ di rumah sakit tersier di Bali. Penelitian retrospektif potong lintang ini dlikaukan pada Januari 2018- Desember 2020 di Rumah Sakit Umum Pusat Sanglah, Bali. Identifikasi bakteri dan uji sensitivitas antibiotik dilakukan dengan alat otomatis Vitek®2 Compact. Hasil penelitian menunjukkan dari 2972 isolat, 1067 (63,82\%) isolat adalah E. coli penghasil ESBL dan 902 isolat $(69,39 \%)$ adalah $K$. pneumoniae penghasil ESBL. Isolat penghasil ESBL ditemukan terbanyak pada non-ICU (89,39\%). Bakteri E.coli penghasil ESBL menunjukkan sensitivitas $\geq 80 \%$ terhadap Amikacin, Ertapenem, Meropenem, Nitrofurantoin, Piperacillin-tazobactam, dan Tigecycline. Sedangkan, $K$. pneumoniae penghasil ESBL menunjukkan sensitivitas $\geq 80 \%$ terhadap Amikacin, Ertapenem, Meropenem, dan Tigecycline. Penelitian ini menyoroti tingginya prevalensi E.coli dan K.pneumoniae penghasil ESBL di rumah sakit rujukan tersier di Bali. Analisis
\end{abstract}


yang seksama dari antibiogram kedua spesies penghasil ESBL tersebut akan membantu menyusun kebijakan penggunaan antibiotik dan pencegahan, pengendalian penyebaran bakteri penghasil ESBL.

Kata Kunci: Escherichia coli; Klebsiella pneumoniae; Extended Spectrum Beta Lactamases; ICU dan Non-ICU

\section{ABSTRACT}

Antibiotic resistance has increased globally in recent years, especially the incidence of Escherichia coli (E.coli) and Klebsiella pneumoniae (K.pneumoniae) producing Extended Spectrum Beta Lactamases (ESBL). The purpose of this study was to provide an overview of the prevalence and antibiogram of E.coli and K.pneumoniae producing ESBL in tertiary hospitals in Bali. This cross-sectional retrospective study was conducted in January 2018-December 2020 at Sanglah General Hospital, Bali. Bacterial identification and antibiotic sensitivity tests was carried out with the Vitek®2 Compact system. The results showed that from 2972 isolates, 1067 (63.82\%) isolates were ESBL-producing E. coli and 902 isolates (69.39\%) were ESBL-producing K.pneumoniae. ESBL-producing isolates were found mostly in non-ICU (89.39\%). ESBL-producing E.coli bacteria showed sensitivity > $80 \%$ to Amikacin, Ertapenem, Meropenem, Nitrofurantoin, Piperacillin-tazobactam, and Tigecyclin. Meanwhile, ESBL-producing K. pneumoniae showed sensitivity > 80\% to Amikacin, Ertapenem, Meropenem, and Tigecycline. This study highlights the high prevalence of ESBL-producing E.coli and K.pneumoniae in tertiary referral hospitals in Bali. Careful analysis of the antibiograms of the two ESBLproducing species will help formulate policies on the use of antibiotics and the prevention and control of the spread of ESBL-producing bacteria.

Keywords: Escherichia coli; Klebsiella pneumoniae; Extended Spectrum Beta Lactamases; ICU dan Non-ICU

\section{PENDAHULUAN}

Resistansi terhadap antibiotik meningkat sangat cepat dan kemunculannya telah mendapatkan perhatian khusus dalam perkembangan dunia kesehatan dalam abad ke 21 ini (Smith, 2017). Perkembangan penggunaan antibiotik pun meningkat saat dunia kembali diancam pandemi, virus Sars COV-2, penyebab COVID-19. Antibiotik dari golongan Beta-lactam tetap merupakan kelas antibiotik yang paling sering digunakan di berbagai lini. Tetapi, penggunaannya memunculkan resistansi terhadap Beta-lactam oleh suatu enzim Beta-lactamases (Lim et 
al., 2019). Ini adalah penyebab resistansi tersering terhadap golongan antibiotik ini (Rimal, Thapa and Maharjan, 2017). Untuk megatasi efek Beta-lactamases, ditemukan dua jenis antibiotik golongan Beta-lactam yaitu penicillin yang tahan terhadap penicillinase dan cephalosporin generasi pertama, selama tahun 1960-an.

Terapi ini masih bertahan selama lebih dari dua dasawarsa, sampai akhirnya resistansi oleh Beta-lactamases yang dihasilkan oleh bakteri Gram negatif menjadi masalah serius di dunia kesehatan. Untuk mengatasinya, terapi antibiotik cephalosporin dengan spektrum yang luas ditemukan selama tahun 1970-an (Medeiros, 1997). Setelah itu, sekelompok strain Beta-lactamases ditemukan di Jerman (Bilavsky et al., 2014). Strain spesies ini dapat menghidrolisis cephalosporin dengan spektrum yang lebih luas, dan dikenal dengan sebutan Extended Spectrum Beta-Lactamases (ESBLs) (Anthony et al., 2007).

Definisi ESBL yang mengacu pada suatu konsesus tidak ada. ESBLs dapat didefinisikan sebagai grup enzim yang mampu memberikan suatu resistansi terhadap golongan betalactam, diantaranya penicillin, generasi pertama hingga ketiga dari cephalosporin, dan aztreonam (tetapi tidak termasuk cephamycins dan carbapenems) dan menyebabkan tidak efektif (Bradford and Bradford, 2001). Resistansi oleh ESBLs pada Betalactamases dapat ditularkan, dan dihambat oleh golongan clavulanic acid, tazobactam atau sulbactam, dan gen penyandi resistansi ini dapat disebarkan antar bakteri (Paterson and Bonomo, 2005). ESBLs banyak ditemukan pada bakteri Gram negative dari family Entrobacteriaceae, E.coli dan Klebsiella spp (Chaudhary P et al., 2016).

Beberapa faktor risiko terhadap infeksi bakteri penghasil ESBL diantaranya, penggunaan antibiotik yang memanjang, perawatan diruang ICU, prosedur invasif berulang, luka akibat tekanan, anemia, dan pemakaian kateter urin yang menetap (Sharif et al., 2016). Penggunaan antibiotik secara bijak dan efektif, terutama pada ruang ICU sangat penting untuk mencegah berkembangnya resistansi terhadap antibiotik (Barnaby et al., 2014; Kirby, C and R, 2017).

Bakteri yang menghasilkan ESBL lebih sulit untuk dideteksi dengan tehnik pemeriksaan rutin Kirby Bauer untuk mengetahui kepekaan terhadap antibiotik dan dapat menimbulkan false negative (Kumar et al., 2014). Deteksi strain bakteri penghasil ESBL secara fenotif dapat dilakukan dengan alat otomatis berbasis micro broth dilution, Vitek ${ }^{\circledR 2}$ Compact 2, untuk hasil kepekaan yang lebih baik (Harris et al., 
2007; Razazi et al., 2012). Mengetahui keberadaan suatu ESBL penting sehingga dapat digunakan untuk mengukur tingkat resistansi dan mengatur kontrol terhadap infeksi kemudian melakukan tindakan pencegahan penyebarannya.

RSUP Sanglah sebagai rumah sakit rujukan tersier di Bali, memiliki kapasitas 750 tempat tidur, dan juga dilengkapi dengan sarana perawatan ruang intensive. Saat ini belum ada penelitian yang menyajikan data mengenai pola kuman dan karakteristik dari prevalensi E.coli dan K.pneumoniae penghasil ESBL di RSUP Sanglah, terutama ruang ICU. Penyajian data untuk merekam prevalensi dan pola resistansi oleh Enterobacteriaceae penghasil ESBL, dan membantu penerapan kebijakan untuk efektifitas pemakaian antibiotik.

\section{METODE DAN BAHAN}

Penelitian ini dilakukan di RS Sanglah, rumah sakit rujukan tersier dengan 750 tempat tidur dan pusat layanan kesehatan utama di Indonesia bagian timur. Data Escherichia coli dan Klebsiella pneumoniae dan uji sensitivitas antimikroba yang rutin dilakukan di RSUP Sanglah dikumpulkan secara retrospektif dari spesimen klinis pasien tahun 2018 sampai 2020. Penelitian ini telah disetujui oleh Komite Penelitian Etik Universitas Udayana/RSUP Sanglah.

Escherichia coli dan Klebsiella pneumoniae diisolasi dari spesimen klinis termasuk darah, urin, sputum, dan spesimen lain (cairan tubuh lainnya, swab dasar luka, jaringan, feses). Pengelolaan spesimen untuk kultur bakteriologi berdasarkan standar operasional prosedur Departemen Mikrobiologi RSUP Sanglah berdasarkan Clinical Microbiology Procedure Handbook.(Lynne S. Garcia, 2016)

Identifikasi mikroorganisme dan uji sensitivitas antimikroba dilakukan menggunakan metode mikrodilusi dengan sistem Vitek®2 Compact-2 Compact menurut Clinical And Laboratory Standard Institute (CLSI). (Clinical and Laboratory Standards Institute, 2020)

Data dikumpulkan dan dianalisis dengan Microsoft Excel perangkat lunak 2017 secara deskriptif. Perhitungan disajikan dalam tabulasi deskriptif.

\section{HASIL}

Total 2972 isolat, $1067(63,82 \%)$ adalah E.coli penghasil ESBL dan 902 $(69,39 \%)$ isolat K.pneumoniae penghasil ESBL dari sampel klinis. Jumlah terbanyak penghasil ESBL dari isolat E.coli didapatkan dari urine (514) 48,17\%. Dari isolat K.pneumoniae 
didapatkan terbanyak (311) $36,25 \%$

sputum (Tabel 1).

Tabel 1. Sumber dan Jumlah Isolat Escherichia coli dan Klebsiella pneumoniae dari ICU dan non-ICU tahun 2018-2020

\begin{tabular}{|c|c|c|c|c|c|c|c|}
\hline \multirow[b]{2}{*}{ No } & \multirow{2}{*}{$\begin{array}{l}\text { Spesimen dari } \\
\text { ICU dan non- } \\
\text { ICU }\end{array}$} & \multicolumn{2}{|c|}{2018} & \multicolumn{2}{|c|}{2019} & \multicolumn{2}{|c|}{2020} \\
\hline & & $\begin{array}{c}\text { Escherichia } \\
\text { coli }\end{array}$ & $\begin{array}{c}\text { Klebsiella } \\
\text { pneumoniae }\end{array}$ & $\begin{array}{c}\text { Escherichia } \\
\text { coli }\end{array}$ & $\begin{array}{c}\text { Klebsiella } \\
\text { pneumoniae }\end{array}$ & $\begin{array}{c}\text { Escherichia } \\
\text { coli }\end{array}$ & $\begin{array}{c}\text { Klebsiella } \\
\text { pneumoniae }\end{array}$ \\
\hline 1 & Darah & 33 & 60 & 58 & 80 & 31 & 43 \\
\hline 2 & Sputum & 41 & 114 & 48 & 122 & 26 & 101 \\
\hline 3 & Urin & 177 & 79 & 179 & 51 & 158 & 60 \\
\hline 4 & CVC/ CAPD & 2 & 5 & 2 & 4 & 2 & 1 \\
\hline 5 & Cairan Tubuh & 19 & 5 & 9 & 7 & 0 & 5 \\
\hline 6 & Feses & 8 & 1 & 3 & 0 & 4 & 3 \\
\hline \multirow[t]{3}{*}{7} & Jaringan dan & & & & & & \\
\hline & Swab & 85 & 66 & 92 & 53 & 90 & 52 \\
\hline & Total & 365 & 330 & 391 & 317 & 311 & 265 \\
\hline
\end{tabular}

Prevalensi ESBL selama 3 tahun penghasil ESBL didapati berturut dalam dari ruang perawatan ICU dari kedua 3 tahun evaluasi, $36 ; 17 ; 12$ dan isolat E.coli dan K.pneumoniae K.pneumoniae penghasil ESBL berturut mengalami penurunan. Isolat E.coli 54;48;42 (Gambar 1).

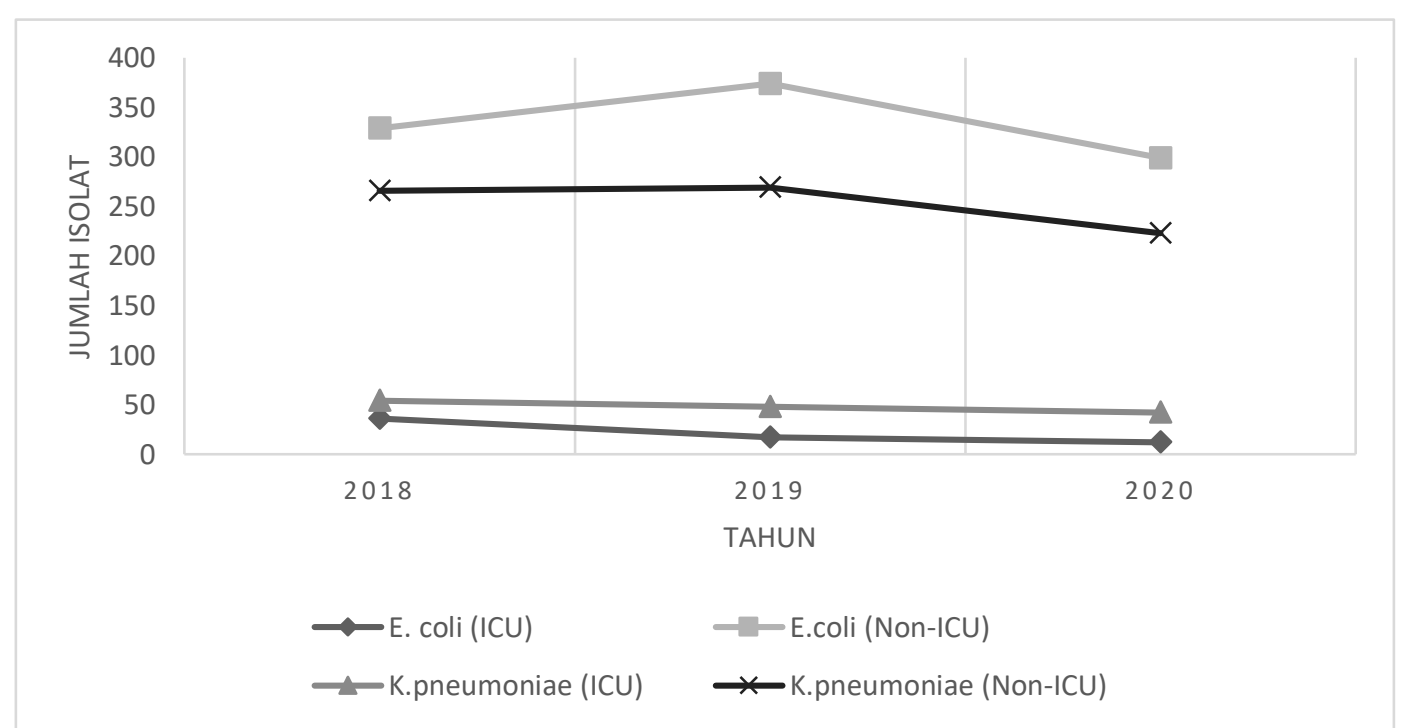

Gambar 1. Jumlah Isolat Escherichia coli dan Klebsiella pneumoniae dari ICU dan NonICU Tahun 2018-2020

Dari Antibiogram bakteri E.coli penghasil ESBL yang menunjukkan sensitivitas $\geq 80 \%$ terhadap Amikacin,
Ertapenem, Meropenem, Nitrofurantoin, Piptazo dan Tigecycline. Pola kepekaan antibiotik dari K.pneumoniae penghasil 
ESBL menunjukkan sensitivitas $\geq 80 \%$ tahun berturut (Tabel 2).

berturut terhadap Amikacin, Ertapenem,

Meropenem, Tigecycline, sedangkan

Nitrofurantoin dan Piptazo memiliki

kepekaan $<80 \%$ pada isolat

K.pneumoniae penghasil ESBL selama 3

Tabel 2. Persentase Suseptibilitas Terapi Pilihan Untuk Escherichia coli dan Klebsiella pneumoniae penghasil ESBL Tahun 2018-2020

\begin{tabular}{llcccccc}
\hline & & \multicolumn{2}{c}{2018} & \multicolumn{2}{c}{2019} & \multicolumn{2}{c}{2020} \\
\cline { 3 - 7 } No & Antibiotik & coli & pneumoniae & coli & pneumoniae & coli & pneumoniae \\
\hline 1 & Amikacin & 96.98 & 92.18 & 98.21 & 83.28 & 98.07 & 91.32 \\
2 & Ertapenem & 99.45 & 97.18 & 99.48 & 98.1 & 99.35 & 97.73 \\
3 & Nitrofurantoin & 90.14 & 20.62 & 93.35 & 17.03 & 88.1 & 11.32 \\
4 & Meropenem & 98.63 & 97.5 & 100 & 98.74 & 100 & 98.87 \\
5 & Tigecycline & 99.73 & 81.56 & 100 & 80.44 & 98.39 & 85.28 \\
6 & Piperacillin- & & & & & & Escherichia \\
& tazobactam & 84.38 & 49.37 & 82.6 & 57.73 & 85.21 & 71.32
\end{tabular}

\section{DISKUSI}

Infeksi yang disebabkan oleh bakteri penghasil ESBL telah muncul secara luas dan menimbulkan masalah, karenanya dalam pemberian terapi dengan antibiotik spektrum luas banyak menimbulkan kegagalan. Penggunaan antibiotik berlebihan dan tidak bijak di lingkungan rumah sakit, terutama di ruang perawatan intensif akan menimbulkan biaya yang tinggi dan menjadi ancaman tidak terduga di kemudian hari yang memicu resistensi terhadap antibiotik, sementara pasien yang mendapat perawatan di rumah sakit lebih peka terhadap kolonisasi dan infeksi berbagai patogen di rumah sakit.

Dalam penelitian ini, dari total 2972 sampel klinis, jumlah isolat Escherichia coli adalah 1672 (56,26 \%) dan isolat K.pneumoniae adalah 1300 $(43,74 \%)$. Hal ini serupa dengan studi surveilans di Eropa dan penelitian di suatu center kesehatan di Indonesia, di mana tingkat isolasi E.coli dari semua sampel klinis relatif lebih tinggi $(39,8 \%)$ (Kronenberg A, Hilty M, Endimiani A, 2013; Anggraini et al., 2018). E.coli penghasil ESBL diisolasi sebagian besar dari sampel urin $(48,17 \%)$, sedangkan pada isolat K.pneumoniae penghasil 
ESBL terbanyak didapatkan dari sampel sputum $(36,25 \%)$. Penelitian lain di tempat berbeda melaporkan tingkat isolasi E.coli dari urin sebesar 15,6\% (2004), 49,8\% (2004) dan 20,4\% (2012) (Babypadmini S, 2004; Tankhiwale SS, Jalgaonkar SV, Ahamad S, 2004; Rajan S, Prabavathy J,Nadu, 2012). Tingkat isolasi K.pneumoniae penghasil ESBL dari sampel sputum pada penelitian lain 19,04\% (Sarojamma and Ramakrishna, 2011).

Studi dari Swiss didapatkan prevalensi E.coli yang resisten terhadap sefalosporin generasi ke-3 5,8\% dan K.pneumonie $4,4 \%$ sedangkan $>50 \%$ E.coli dan K.pneumoniae resisten terhadap sefalosporin generasi ke-3 pada penelitian ini (Kronenberg et al., 2013). Tingginya prevalensi E.coli dan K.pneumoniae yang resisten terhadap sefalosporin generasi ke-3 dalam penelitian kami mungkin disebabkan oleh pemakaian sefalosporin generasi ketiga yang berlebihan untuk mengobati infeksi Gram negatif dan kurangnya kebijakan penggunaan antibiotik di rumah sakit yang diatur di negara kami (Kumar MS, Lakshmi V, 2006).

Kejadian ESBL di rumah sakit, terutama ruang perawatan ICU bervariasi di berbagai belahan dunia. Sebuah penelitian oleh Canadian National Intensive Care Unit (CANICU) yang pertama mendokumentasikan bahwa E.coli penghasil ESBL menjadi lebih umum daripada Klebsiella spp penghasil ESBL di ICU (Zhanel et al., 2008). Tetapi pada penelitian ini didapatkan isolat K.pneumoniae penghasil ESBL lebih banyak muncul dibandingkan ESBL pada E.coli.

Hasil penelitian menunjukkan selama 2018 sampai 2020 penghasil ESBL terbanyak dari spesimen urin. Hal ini dapat disebabkan oleh fakta bahwa infeksi saluran kemih adalah salah satu infeksi paling umum yang ditemui dalam praktik klinis (Tan and Chlebicki, 2016).

Di penelitian kami, sensitivitas terhadap Amikacin, Ertapenem, Meropenem, Nitrofurantoin, Piptazo dan Tigecycline masih di atas $80 \%$ pada isolat E.coli penghasil ESBL, sedangkan pada K.pneumoniae penghasil ESBL sensitivitas Amikacin, Ertapenem, Meropenem, Tigecycline masih di atas $80 \%$. Pada isolate K.pneumoniae penghasil ESBL sensitivitas pada 2 jenis antibiotik, Nitrofurantoin dan Piptazo rendah karena menunjukkan resistensi yang meningkat.

Multi resistansi antibiotik mungkin disebabkan oleh sejumlah faktor seperti pengobatan sendiri yang tidak tepat, kurangnya peraturan peresepan, obat-obatan di bawah standar atau dipalsukan dan penggunaan antibiotik pertanian (Tanwar et al., 
2014). Karena Escherichia coli dan Klebsiella pneumoniae yang memproduksi ESBL menjadi semakin resisten terhadap berbagai obat, akan ada batasan besar dalam pemilihan obat dalam perawatan pasien.

\section{SIMPULAN}

Penelitian ini menyoroti tingginya prevalensi E.coli dan K.pneumoniae penghasil ESBL di rumah sakit rujukan tersier di Bali. Analisis yang seksama dari antibiogram kedua spesies penghasil ESBL tersebut akan membantu menyusun kebijakan penggunaan antibiotik dan pencegahan, pengendalian penyebaran strain E.coli dan K.pneumoniae penghasil ESBL. Disarankan untuk rutin melakukan deteksi terhadap ESBL sehingga dapat mengurangi risiko terjadinya resistansi dan meningkatkan efektivitas pelaksanaan pencegahan dan pengendalian infeksi.

\section{KONFLIK KEPENTINGAN}

Para penulis melaporkan tidak ada konflik kepentingan. Penulis memberikan penghargaan atas dukungan Rumah Sakit Sanglah dan peserta pendidikan dari Departemen Mikrobiologi Klinik dalam masa studi.

\section{REFERENSI}

Enterobacteriaceae Penghasil ESBL di RSUD Arifin Achmad Pekanbaru," Jurnal Kedokteran Brawijaya [Preprint]. doi:10.21776/ub.jkb.2018.030.01.9.

Anthony, D.H. et al. (2007) "How important is patient-to-patient transmission in extended-spectrum beta-lactamase Escherichia coli acquisition," American journal of infection control, 35(2), pp. 97101.

doi:10.1016/J.AJIC.2006.09.011.

Babypadmini S, A.B. (2004) "Extended spectrum -lactamases in urinary isolates of Escherichia coli and Klebsiella pneumoniae - prevalence and susceptibility pattern in a tertiary care hospital.," Indian $J$ Med Microbiol., 22;Jul-Se, p. (3):172-4.

Barnaby, E.Y. et al. (2014) "A prospective observational study of the prevalence and risk factors for colonization by antibiotic resistant bacteria in patients at admission to hospital in Singapore," $B M C$ infectious diseases, 14(1). doi:10.1186/1471-2334-14-298.

Bilavsky, E. et al. (2014) "Risk factors for colonization with extendedspectrum beta-lactamase-producing enterobacteriaceae on admission to rehabilitation centres," Clinical microbiology and infectio: the official publication of the European Society of Clinical Microbiology and Infectious Diseases, 20(11), pp. O804-O810. doi:10.1111/14690691.12633.

Bradford, P.A. and Bradford, P.A. (2001) "Extended-Spectrum $\beta$ Lactamases in the 21st Century: Characterization, Epidemiology, and Detection of This Important Resistance Threat ExtendedSpectrum $\square$-Lactamases in the 21st Century: Characterization, Epidemiology, and Detection of 
This

doi:10.1128/CMR.14.4.933.

Chaudhary P, Bhandari D, Thapa K, Thapa P, Shrestha D, Chaudhary HK, Shrestha A, Parajuli H, G.BP. (2016) "Prevalence of Extended Spectrum Beta-Lactamase Producing Klebsiella Pneumoniae Isolated From Urinary Tract Infected Patients," J Nepal Health Res Counc, May;14(33), pp. 111115 .

Clinical and Laboratory Standards Institute (2020) CLSI M100 30th Edition, Journal of Services Marketing.

Harris, A.D. et al. (2007) "Risk factors for colonization with extendedspectrum $\beta$-lactamase- producing bacteria and intensive care unit admission," Emerging Infectious Diseases, 13(8), pp. 1144-1149. doi:10.3201/EID1308.070071.

Kirby, A., C, B. and R, W. (2017) "Antibiotic consumption and Enterobacteriaceae skin colonization in hospitalized adults," The Journal of hospital infection, 95(1), pp. 65-68. doi:10.1016/J.JHIN.2016.09.012.

Kronenberg, A. et al. (2013) "Temporal trends of extended-spectrum cephalosporin- resistant Escherichia coli and Klebsiella pneumoniae isolates in in- and outpatients in Switzerland, 2004 to," Eurosurveillance, 18(21), pp. 1-10. doi:10.2807/ese.18.21.20484-en.

Kronenberg A, Hilty M, Endimiani A, M.K. (2013) "Temporal trends of extended-spectrum cephalosporinresistant Escherichia coli and Klebsiella pneumoniae isolates in in- and outpatients in Switzerland, 2004 to 2011.," Euro Surveill., 18(21):204.

Kumar, D. et al. (2014) "Antimicrobial Susceptibility Profile of Extended
Spectrum $\quad \beta$-Lactamase (ESBL) Producing Escherichia coli from Various Clinical Samples," Infectious Diseases: Research and Treatment, 7, p. IDRT.S13820. doi:10.4137/idrt.s13820.

Kumar MS, Lakshmi V, R.R. (2006) "Occurrence of extended spectrum beta-lactamases among Enterobacteriaceae spp. isolated at a tertiary care institute.," Indian $J$ Med Microbiol., July, pp. 24(3):208-11.

Lim, S. et al. (2019) "Clinical prediction models for ESBLEnterobacteriaceae colonization or infection: a systematic review," The Journal of hospital infection, 102(1), pp. 8-16. doi:10.1016/J.JHIN.2019.01.012.

Lynne S. Garcia (2016) Clinical Microbiology Procedures Handbook, Clinical Microbiology Procedures Handbook. Edited by H.D. Isenberg and (Deceased). doi:10.1128/9781555818814.

Medeiros, A. a (1997) "Recent increases in resistance: mechanisms and organisms. Evolution and Dissemination of / 3-Lactamases Accelerated by Generations of (3Lactam Antibiotics," Clinical Infectious Diseases, 24(Suppl 1), pp. 19-45.

Paterson, D.L. and Bonomo, R.A. (2005) "Clinical Update ExtendedSpectrum Beta-Lactamases: a Clinical Update," Clinical Microbiology Reviews, 18(4), pp. 657-686. doi:10.1128/CMR.18.4.657.

Rajan S, Prabavathy J,Nadu, T. (2012) "Antibiotic Sensitivity and Phenotypic Detection Of ESBL producing E . Coli Strains Causing Urinary Tract Infection In a Community Hospital, Chennai, Antibiotic Sensitivity and Phenotypic Detection Of ESBL 
producing E. Coli Strains Causing Urinary Tract," pp. 1-15.

Razazi, K. et al. (2012) "Clinical impact and risk factors for colonization with extended-spectrum $\beta$ lactamaseproducing bacteria in the intensive care unit," Intensive Care Medicine, 38(11), pp. 1769-1778. doi:10.1007/S00134-012-2675-0.

Rimal, U., Thapa, S. and Maharjan, R. (2017) "Prevalence of Extended Spectrum Beta-Lactamase Producing Escherichia coli and Klebsiella species from Urinary Specimens of Children attending Friendship International Children's Hospital," Nepal Journal of Biotechnology, 5(1), pp. 32-38. doi:10.3126/njb.v5i1.18868.

Sarojamma, V. and Ramakrishna, V. (2011) "Prevalence of ESBLProducing Klebsiella pneumoniae Isolates in Tertiary Care Hospital," ISRN Microbiology, 2011, pp. 1-5. doi:10.5402/2011/318348.

Sharif, M.R. et al. (2016) "Prevalence and Risk Factors associated with Extended Spectrum Beta Lactamase Producing Escherichia coli and Klebsiella pneumoniae Isolates in Hospitalized Patients in Kashan (Iran)," Electronic physician, 8(3), pp. 2081-2087. doi:10.19082/2081.

Smith, M. (2017) "Antibiotic Resistance Mechanisms," Journeys in Medicine and Research on Three Continents Over 50 Years, (May 2017), pp. 95-99. doi:10.1142/9789813209558_0015.

Tan, C.W. and Chlebicki, M.P. (2016) "Urinary tract infections in adults," Singapore Medical Journal, 57(9), pp. 485-490. doi:10.11622/smedj.2016153.

Tankhiwale SS, Jalgaonkar SV, Ahamad S, H.U. (2004) "Evaluation of extended spectrum beta lactamase in urinary isolates.," Indian $\mathrm{J} \mathrm{Med}$ Res., December, pp. 120(6):553-6.

Tanwar, J. et al. (2014) "Multidrug resistance: An emerging crisis," Interdisciplinary Perspectives on Infectious Diseases, 2014. doi:10.1155/2014/541340.

Zhanel, G.G. et al. (2008) "Antimicrobial-Resistant Pathogens in Intensive Care Units in Canada: Results of the Canadian National Intensive Care Unit (CAN-ICU)," 52(4), pp. 1430-1437. doi:10.1128/AAC.01538-07. 